\title{
Correspondence
}

\author{
Letters to the Editor should not exceed 500 words.
}

\section{Hospital Medical Staffing}

SIR,-The agreement between the Ministry and profession on the subject of hospital medical staffing has received scant notice in the medical press, but acceptance of the Platt Report is probably the most important step that has been made in the hospital service since the inception of the N.H.S. The exercise which started with the appointment of the Platt Working Party in July 1958 ended its initial stage with the publishing of its Report in March 1961. ${ }^{1}$ Facts and figures hitherto unknown were published and certain recommendations were put forward. The Ministry accepted the Report but the profession reserved its position until the need for the new medical assistant grade could be substantiated.

During the next two and a half years regional boards and boards of governors carried out a vast investigation into their staffing requirements and the basic figures were published in the Ministry document which appeared in the British Medical fournal (15 August, p. 438).

If we confine our attention to the consultant establishment we find that some regions asked for a consultant increase of $45-49 \%$, while at the other extreme the figure was $9 \%$. In round figures 1,806 whole-time equivalents of consultant service were requested over a five-year period-an increase of 360 per annum. To this demand must be added about 1,400 (280 a year) which is the estimated figure for loss due to retirement or death.

It might be assumed that the surplus senior registrars and promoted S.H.M.O.s could meet the demand, but this can only be temporary, since a brief glance at the manpower situation shows an alarming state of affairs which is becoming increasingly serious. Take, for example, the output of medical graduates in 1955 (Platt, paragraph 93) as 1,800 . This is the group from whom some consultants might be expected to appear in 1965-6. Of the 430 women only a small proportion could be expected to play a permanent part in hospital staffing because marriage is particularly likely to interrupt training in any specialty, and no matter what views are held on the extent of emigration we can assume that at least 200 may be lost to the service for this reason.

With the original figure now reduced to about 1,200 there will be a replacement demand for 280 consultants and about twice that number of general practitioners, say a total of 800 . This leaves a residue of 400 to which must be added that proportion of the 430 women graduates who remain in active service. From this figure the demands of other branches of medicine as well as any expansion in the hospital field will have to be met.

Competition is inevitable, and, even if the figures are less pessimistic than given, any page 816 appreciable accelerated expansion in the hospital field can only take place at the expense of some other branch. The recent rate of increase has been of the order of $2 \%$ a year, of which more than half have been foreign graduates. In addition, if the consultant grade is to be enlarged properly trained candidates must be available. Dilution in consultant quality cannot be countenanced.

Taking it overall, it is probable that no more than 500 new consultants can be provided each year and of these half or more are replacements. This simple piece of arithmetic was the basic argument for adjusting the Board's demands to a figure that might possibly be met. The adjusted figure of 1,095 from the original request for 1,806 is the reduction of 700 mentioned in your leader (15 August, p. 398).

Manpower shortage is bound to loom large in any current discussions. The seriousness of this was not fully appreciated until quite recently, in fact until the studies made at the time of the Platt Working Party. The Willink Committee unhappily recommended a reduction of $10 \%$ of the intake into medical schools and although this has been remedied, and indeed added to by a further $15 \%$, the impact of this increase will not be noticed for at least 12 to 15 years at consultant level.

The student intake was at its lowest in 1960-1-at 1,788, and, even though it has risen to 2,153 by 1963 and will rise further, it is obviously inadequate to meet the overall demands. What the target figure should be and how it should be attained is anyone's guess. Professor Kenneth Hill has made an attempt ${ }^{2}$ but it will take superhuman skill to assess how many overseas graduates will be available for the hospital services; whether the population increase will be constant; whether space will be available for new consultants to work in; whether every specialty and region will be able to attract enough doctors to meet the demand, and so on. All of this inevitably is linked with availability of finance for new medical schools (remembering that one medical student costs twice as much as a student in nearly every other faculty), facilities for medical education, changes in the curriculum and so on.

The other aspect of the Platt Report that has occasioned anxiety is the creation of the medical assistant grade. The fears that many intermediate posts would be freely and permanently filled by a group of doctors who would inevitably perpetuate the worst features of the S.H.M.O. grade could be real if recruitment into this grade was uncontrolled. It must be plainly stated that the Ministry's conception is that this type of appointment should be strictly limited and subject to regular scrutiny and control. On the profession's side every safeguard against improper use has been put forward and has been accepted by the Ministry, but possibly the best safeguard lies in the mechanism by which application for a new post in this grade will have to be made.

In the first place the request will come from the periphery, where it must be shown that the post cannot be adequately filled by the normal process of advertisement. Next, at regional level a professional committee, including representatives of the Regional Consultants and Specialists Committee, will consider the application in relation to its lack of suitability for training, the difficulty in filling it in the past, and so on, before forwarding the application centrally. At Ministry level a combined committee of the profession and Ministry officers will scrutinize all applications and determine their suitability before permitting them to be advertised. This committee, which under the name of the Advisory Committee on Consultant Establishments has sanctioned consultant expansion to the tune of 1,000 new appointments between 1959 and 1963, unheralded and unsung, will include doctors from the periphery and from the specialties concerned.

No one views the future of this grade with equanimity or complacency. The problems and difficulties are obvious, but if handled properly and in accordance with the recommendations of the Platt Report it will provide a career for conscientious practitioners who can give valuable service to the hospitals with a sense of security of tenure.

With the creation of the medical assistant grade the S.H.M.O. vanishes. Over the past years a great deal, though not everything, has been done for S.H.M.O.s whose service has been so valuable. The problems have been many and varied and not easy of solution, but it should be appreciated that the Minister granted a no-detriment clause to a small group of these officers who might otherwise, in the process of review and rearrangement, suffer financial hardship through no fault of their own.

Platt was an exercise that should have been undertaken long before 1958, but it finally produced a monument of paper, figures, and analyses which should help to keep the staffing requirements in better perspective and under constant review.

An important, if not obvious, side-issue of all the meetings and subsequent discussions was the steady development of a better understanding and co-operation between the representatives of the profession and the Ministry. Argument and sharp differences of opinion are only to be expected during discussions, but as the profession is slowly being taken into partnership in many aspects of planning it can be safely assumed that it will adopt a more decisive constructive role than it has done in the past.-I am, etc.,

\section{London N.W.1. T. Holmes Sellors.}

\section{REFERENCES}

1 Medical Staffing Structure in the Hospital Service, Report of the Joint Working Party, 1961. H.M.S.O., London.

2 Hill, K. R., Lancet, 1964, 2, 517. 